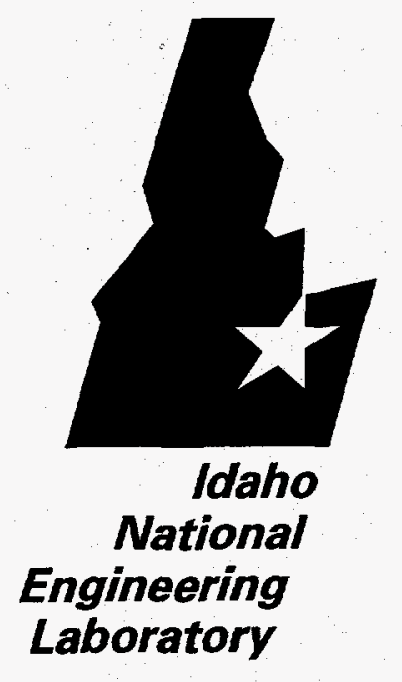

RECEIVED

March 1995

OCT 201995

OSTI

Small Pipe Characterization

System (SPCS) Conceptual Design

M. O. Anderson

T. A. Ferrante

M. D. McKay

בیLlockheed

Idaho Technologies Company

DISTRIBUTION OF THIS DOCUMENT IS UNLIMTED if

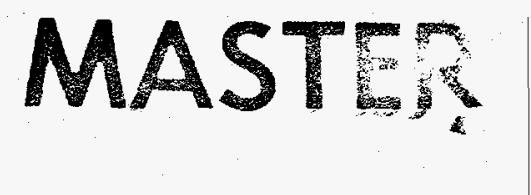


This report was prepared as an account of work sponsored by an agency of the United States Government. Neither the United States Government nor any agency thereof, nor any of their employees, makes any warranty, express or implied, or assumes any legal liability or responsibility for the accuracy, completeness, or usefulness of any information, apparatus, product, or process disclosed, or represents that its use would not infringe privately owned rights. Reference herein to any specific commercial product, process, or service by trade name, trademark, manufacturer, or otherwise does not necessarily constitute or imply its endorsement, recommendation, or favoring by the United States Government or any agency thereof. The views and opinions of authors expressed herein do not necessarily state or reflect those of the United States Government or any agency thereof.

\title{
Small Pipe Characterization System (SPCS) Conceptual Design
}

M. O. Anderson

T. A. Ferrante

M. D. McKay

Published January 1995

\section{Idaho National Engineering Laboratory Applied Engineering Development Laboratory Lockheed Idaho Technologies Company Idaho Falls, Idaho 83415}

\author{
Prepared for the \\ U.S. Department of Energy \\ Assistant Secretary for Environmental Management \\ Under DOE Idaho Operations Office \\ Contract DE-AC07-94ID13223
}




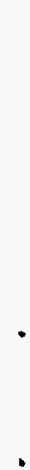

. 


\section{DISCLAIMER}

Portions of this document may be illegible in electronic image products. Images are produced from the best available original document. 


\section{Contents}

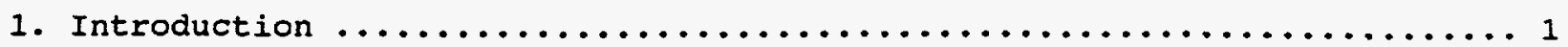

2. Definitions $\ldots \ldots \ldots \ldots \ldots \ldots \ldots \ldots \ldots \ldots \ldots \ldots \ldots \ldots \ldots \ldots \ldots \ldots \ldots$

3. Functional Requirements $\ldots \ldots \ldots \ldots \ldots \ldots \ldots \ldots \ldots \ldots \ldots \ldots \ldots \ldots \ldots$

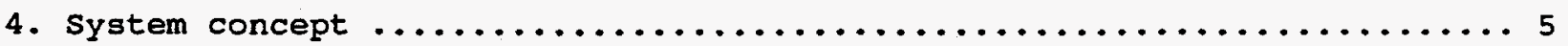

4.1 Mechanical ................................ 5

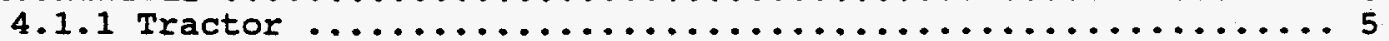

4.1.1.1 Drive Unit $\ldots \ldots \ldots \ldots \ldots \ldots \ldots \ldots \ldots \ldots \ldots, 8$

4.1.1.2 Spring Linkage $\ldots \ldots \ldots \ldots \ldots \ldots \ldots \ldots \ldots \ldots, 8$

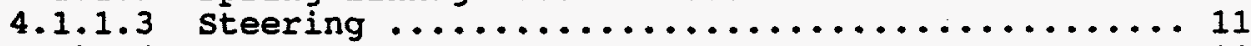

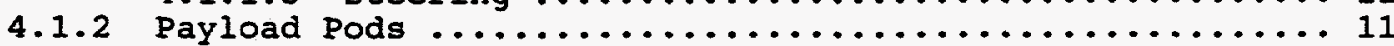

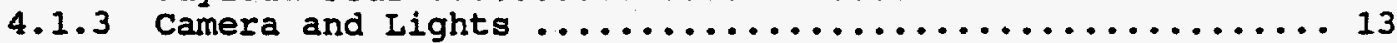

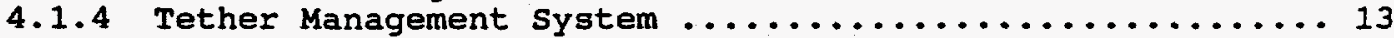

4.1.4.1 Totally Passive Method ...................... 13

4.1.4.2 Passive / Active Method .................. 14

4.1.4.3 Totally Active Method ....................... 14

4.1 .5 Emergency Retrieval System .................. 14

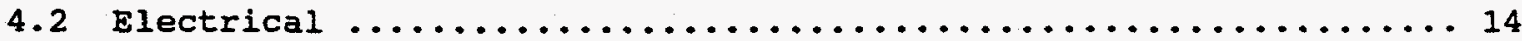

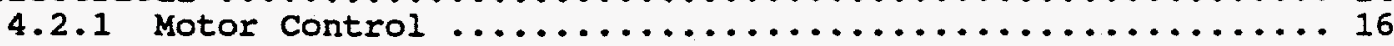

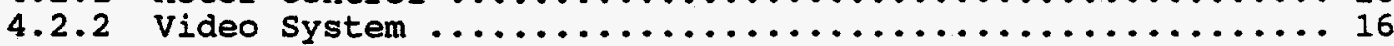

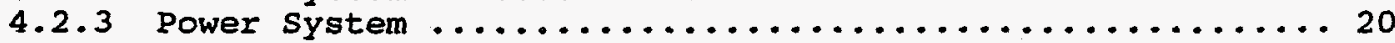

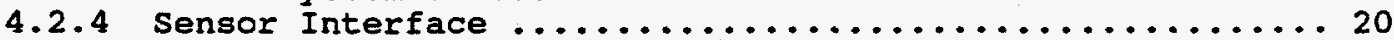

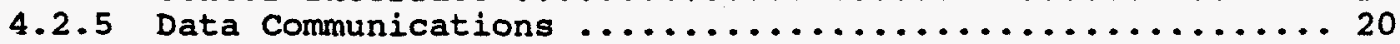

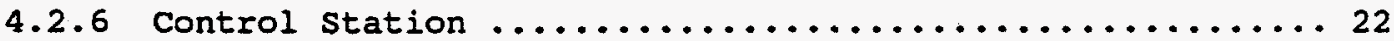

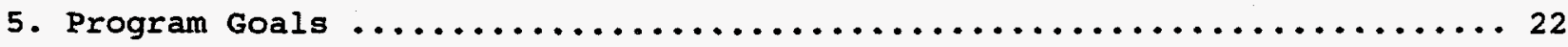

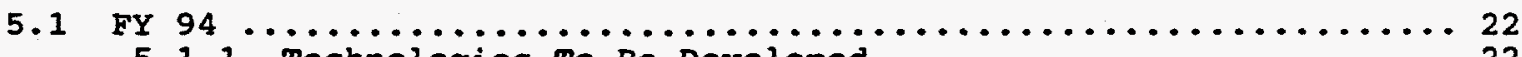

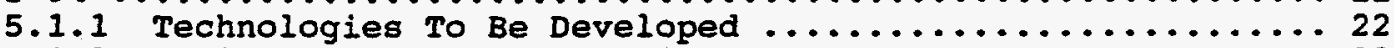

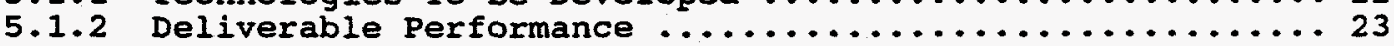

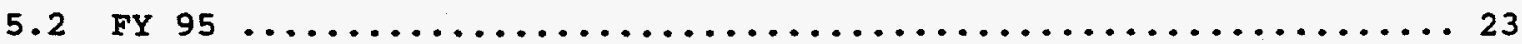

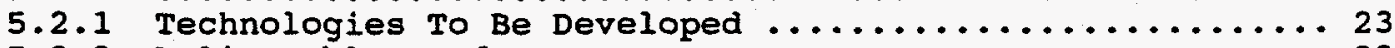

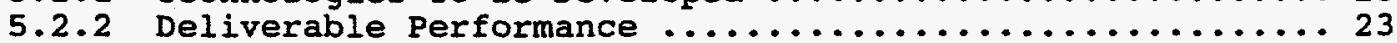

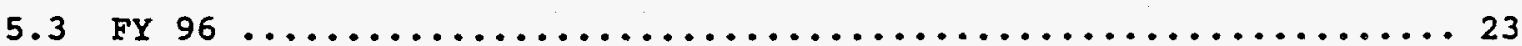




\section{Figures}

1

Pipe Crawling Robot Configuration ............... 6

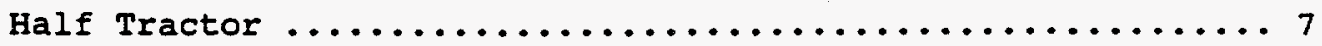

Base Drive Unit $\ldots \ldots \ldots \ldots \ldots \ldots \ldots \ldots \ldots \ldots \ldots \ldots \ldots$.

Half Tractor Traversing An Elbow .................. 10

Motion Transmission In steering system ............. 12

Electrical System Block Diagram ................. 15

Pulse width Modulation ...................... 17

Closed Loop Feedback Control scheme ................. 18

Video system Block Diagram ..................... 19

Data Communications Block Diagram ................. 21

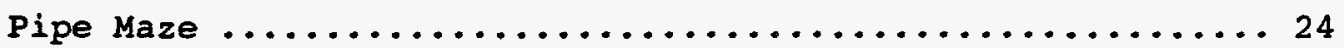




\section{Introduction}

Throughout the Department of Energy (DOE) complex there are many facilities that have been identified for Decontamination and Decommissioning (D\&D). processes are terminated or brought off-line, facilities are placed on the inactive list, and facility managers and site contractors are required to assure a safe and reliable decommissioning and transition of these facilities to a clean final state. Decommissioning of facilities requires extensive reliable characterization, decontamination and in some cases dismantlement. Characterization of piping systems throughout the DOE complex is becoming more and more necessary. In addition to decommissioning activities, characterization activities are performed as part of surveillance and maintenance $(S \& M)$. Because of the extent of contamination, all inactive facilities require some type of $S \& M$. These $S \& M$ activities include visual assessment, equipment and material accounting, and maintenance.

The majority of the inactive facilities have piping systems 3 inches or smaller that are inaccessible because they are contaminated, imbedded in concrete, or run through hot cells. Many of these piping systems have been inactive for a number of years and there exists no current system condition information or the historical records are poor and/or missing altogether. Many of these piping systems are placed on the contaminated list, not because of known contamination, but because of the risk of internal contamination. Many of the piping systems placed on the contamination list may not have internal contamination. Because there is a potential however, they are treated as such. The cost of D\&D can be greatly reduced by identifying and removing hot spot contamination, leaving clean piping to be removed using conventional methods. Accurate characterization of these piping systems is essential before, during and after all D\&D activities. Currently there are no reliable methods for in situ characterization of internal piping 3 inches or smaller. Limited video inspections can be performed using small video cameras by pushing the camera down the pipe. This technique is limited to very short distances and cannot pass more than two 90-degree elbows or traverse vertical runs. As such, characterization is either not performed or assumed by performing solution sampling at valve openings, accessible tanks, historical data when available, etc.

There exist current technologies for remotely characterizing large piping. However, the ability to accurately characterize small piping is not currently available. The Small Pipe Characterization System (SPCS) has been conceived to meet this need. The SPCS can perform the needed characterizations, greatly reducing the cost of D\&D throughout the DOE complex. As well as a cost savings, the small pipe characterization system could greatly reduce the amount of waste associated with D\&D activities by identifying those systems which are not contaminated, thus reducing the amount of material sent to waste handing and storage facilities. 
The piping located at various DOE facilities were mostly used as part of process systems. The piping systems needing characterization are made up of all sizes of pipe within this range; thus to develop a fixed size device would limit the fundamental capability of pipe characterization. As such, the spcs concept outlined in this document identifies a design which ultimately can characterize any piping system within the 1 to 3 inch range without any manual re-configuration or removal from the pipe. The sPCs will be able to adapt to varying pipe sizes and obstacles "on-the-fly." The development and demonstration of the spcs will greatly increase the ability to characterize the massive amounts of piping located throughout the DOE complex. In addition, the SPCS can be used to inspect many other piping systems within the Department of Defense (DOD), industry, and the private sector. Finally, the SPCS technology, upon completion and demonstration, will be transferred to private industry for production.

The development of the spcs will be broken up into two stages. The first stage will produce a useable system on 2 to 3 inch diameter piping. This system will utilize existing camera and radiation systems, data power transmission via tether, and emphases demonstrating the mechanical design. The second stage will produce a useable inspection system for the full 1 to 3 inch diameter piping. The improvements to this system will include a minimal tether with tether management system, on-board power supplies, video/radiation data multiplex, and state-of-the-art miniature electronics. 


\section{Definitions}

Robot - The pipe crawling platform that enters the piping system. Also called "pipe crawler" or "vehicle".

Control station - The hardware console at which the operator sits and operates the robot. The operator can see and record all applicable data and video.

Tether - 1) minimal configuration: A single optic fiber used for data transfer. 2) maximum configuration: A cable of metal conductors and/or optic fibers used for data transfer andor power transmission.

Emergency retrieval system - A tensile member payed out from the vehicle and used to pull the vehicle from the pipe if necessary. Considered to be separate from the tether since alternate retrieval methods do not require this line.

Video camera - Usually refers to the CCD sensor chip and lens mounted on the pipe crawler. The complete system includes the video processor located at the control station.

Payload pods - Small egg-shaped containers that carry payload items such as power supplies, electronics, and sensors.

Drive unit - Consists of one or two gearmotors mounted on the drive wheel. One gearmotor provides the drive, the second gearmotor, when used, is used to steer the drive unit.

Link segments - Small rigid members that are connected at spring joints to form a spring link. Each link segment fits through a 1-in. elbow.

Spring linkage, or linkage - The mechanical parts that connect the drive units. Its function is to press the drive wheels against the walls of the pipe to maintain traction.

Half tractor - A triangular shaped arrangement of three drive units connected by two spring linkages.

Tractor - Two half tractors in series. This is the smallest unit capable of traversing a tee.

"on the fly" - Refers to the ability of the pipe crawler to adapt to different sizes of pipes while inside the piping system. This is opposed to removing the robot from the pipe and reconfiguring it to fit in a different size range.

Pipe maze - A piping system constructed for testing and demonstrating the capabilities of the sPCS. 


\section{Functional requirements}

The SPCS functional requirements are listed in Table 1 . The items on the requirements column are the required system capabilities that the SPCS conceptual design will meet and be demonstrated. The items listed in the desired features column are those functions and capabilities that are not required but will be implemented if possible.

Table 1

\begin{tabular}{|c|c|}
\hline Requirements & Desired Features \\
\hline \multicolumn{2}{|l|}{ Self Propelled } \\
\hline Negotiate Bends & Mitered 90's \\
\hline Negotiate Tees & Mitered Tees \\
\hline \multicolumn{2}{|l|}{ Negotiate Valve (full open) } \\
\hline \multicolumn{2}{|l|}{ Ascend/Descend Vertical } \\
\hline Define Travel Distance (exceed 100') & $250^{\prime}$ One Way Range \\
\hline Negotiate 4 Fittings Minimum & Negotiate Unlimited Fittings \\
\hline \multicolumn{2}{|l|}{ Bi-directional Drive } \\
\hline \multicolumn{2}{|l|}{$1^{\prime \prime}$ to $3^{\prime \prime}$ Change on Fly } \\
\hline Deploy Radiation \& Video Sensors & Interchangeable Sensor Interface \\
\hline Manual Control & Supervisory/Autonomous Control \\
\hline Variable speed & Continuously Variable speed \\
\hline Direction \& Distance & 3D Maps \\
\hline \multicolumn{2}{|l|}{ Manage Tether } \\
\hline Transportable & Recoverable \\
\hline \multirow[t]{6}{*}{ Variable speed } & Robust \\
\hline & Using Existing Technology \\
\hline & Reoccurring Costs Less than $\$ 15 \mathrm{~K}$ \\
\hline & Negotiate Surface Irregularities \\
\hline & Interchangeable Components \\
\hline & Environmentaliy sealed \\
\hline
\end{tabular}




\section{System concept}

The Small Pipe Characterization System consists of a control computer located outside the piping to be inspected, a tether for data communications, and a pipe crawling robot. The operator controls the robot from the control computer. The robot is driven by dc-motor-powered wheels arranged in a triangle shaped configuration and sprung against the sides of the pipe for traction as shown in Figure 1. The triangle configuration of the wheels allows the pipe crawler to adapt to changing pipe sizes "on the fly" without manually reconfiguring the robot. Video data, other sensor data, robot system status, and robot commands are passed between the control computer and the robot through a digital bidirectional fiber optic tether. This tether is payed out from the robot as it travels in the pipe. On the return trip the tether will either be payed out as before, pulled from the pipe at the entrance, or reeled back onto the robot.

The operator station will provide real time video and sensor readings along the pipe, as well as other relevant system status information (e.g., distance and direction). If the robot needs to be retrieved by hand, it can be pulled from the pipe with a strong monofilament that is payed out along with the fiber optic tether.

\subsection{Mechanical}

The Pipe Crawler consists of a video camera, two tractors, a radiation sensor and a tether management system. Also included are the electronics and power supplies necessary to run these systems. The radiation sensor and electronics are located in payload pods between the tractors. The entire pipe crawler system is shown in Figure 1.

\subsubsection{Tractor}

Three drive units are connected in a triangular arrangement by a linkage that applies pressure between the wheels and the pipe walls for traction and allows the tractor to adapt to pipe sizes with inner diameters from 1 to 3 inches. The two drive units contacting the same wall form the base of the triangle and are called the Base Drive Units. The drive unit touching the opposite wall is the Top Drive Unit. An additional motor and gearbox for "steering" the wheels is included in the top drive unit. All three wheels are steered by the single steering motor using a flexible coupling and drive shaft arrangement. These components together are called a Half Tractor, shown in Figure 2 .

The half tractor is configured so that when it is correctly oriented with a tee or elbow, it will flex and pass through the 90-degree direction change. The spring linkage allows the flex, and the steering mechanism allows the half tractor to be correctly oriented with respect to the elbow or tee. 
Figure 1. Pipe Crawling Robot Configuration

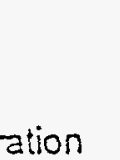

$2 \int^{\frac{\pi}{0}}$

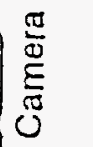

\begin{tabular}{l}
0 \\
$\stackrel{0}{0}$ \\
0 \\
0 \\
\hline
\end{tabular}

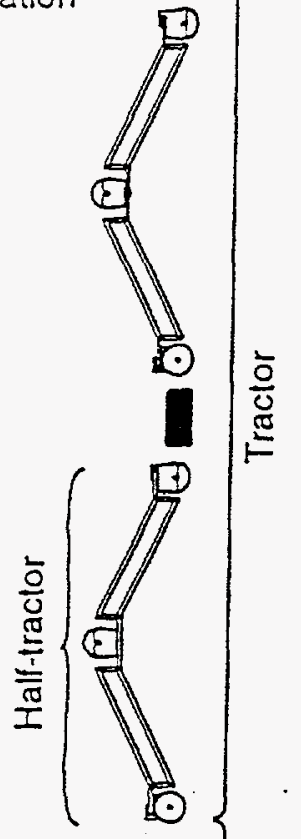

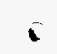

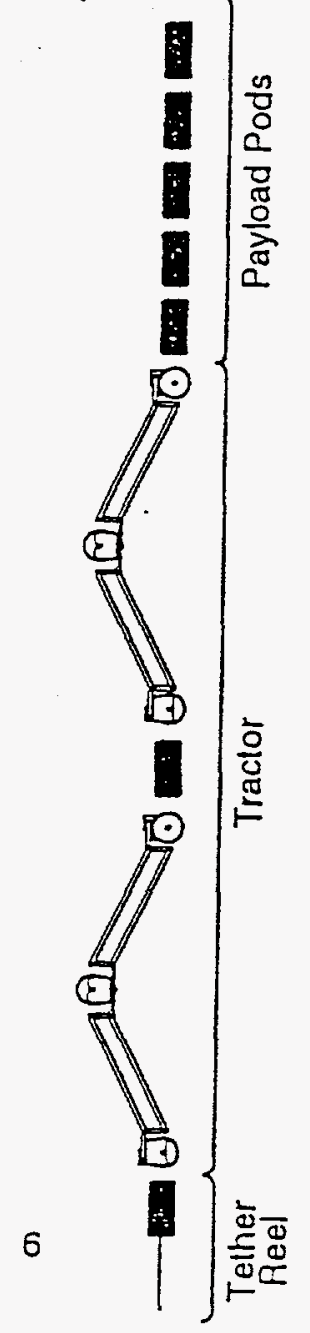


Figure 2. Half Tractor

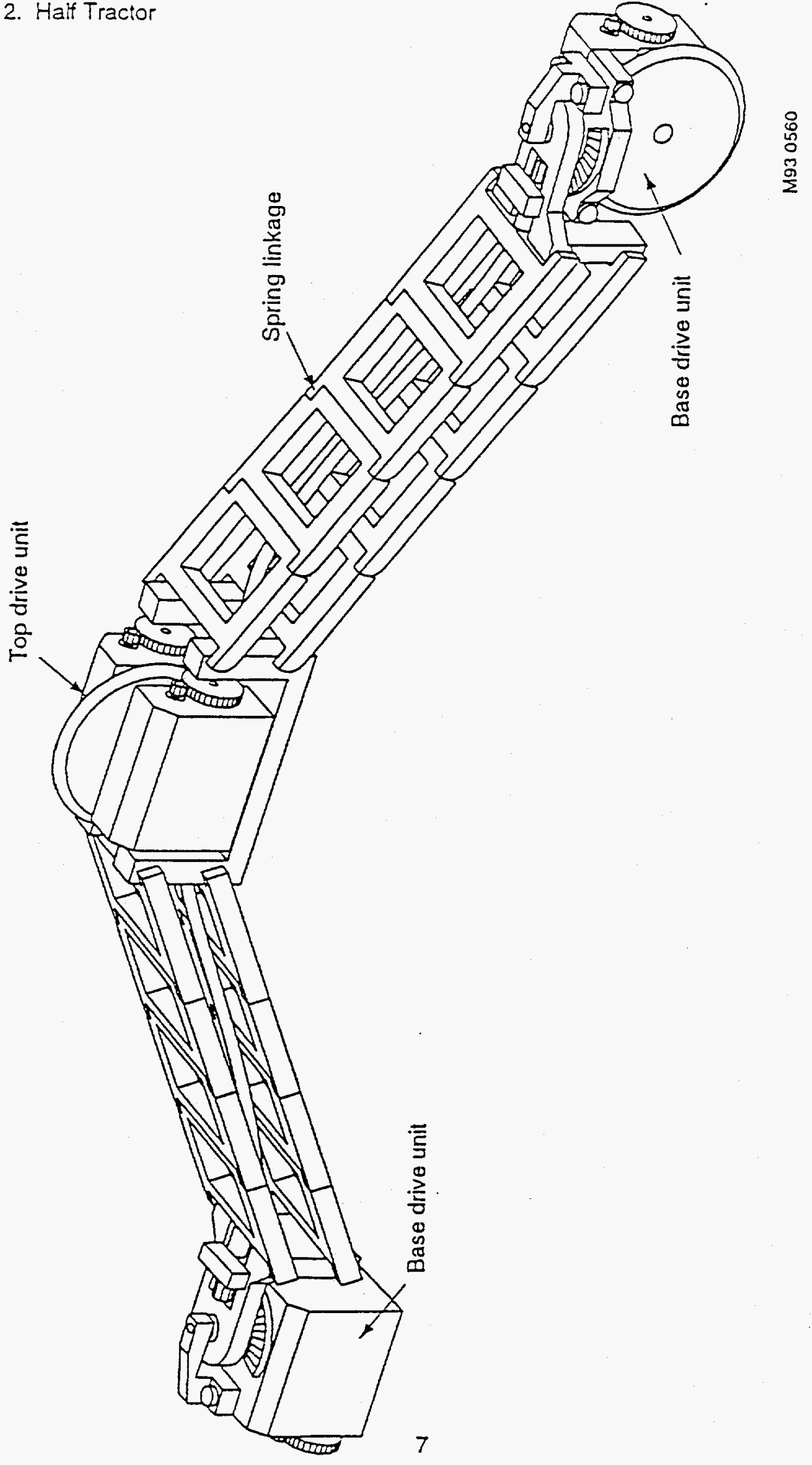


During the movement through a cross union, the wheels of a half tractor may lose traction and a second half tractor must push or pull to help the first through the tee. For this reason, two half tractors are connected in series to negotiate fittings in piping. This combination of two half tractors is the smallest modular unit mechanically able to traverse piping systems and is called the Tractor. Tractors can be connected in series to carry payload pods between them. A minimum of two tractors connected in series is necessary in order to carry the requisite electronics.

\subsubsection{Drive Units}

The most basic component of the SPCS drive system is the Drive Unit. The drive unit consists of a gearmotor. The gearmotor is a combination of motor, gearbox and wheel in a compact configuration. Figure 3 shows the base drive unit. As stated in section 4.1 .1 , the top drive unit is similar to the base drive unit, with the addition of a drivemotor for steering.

\subsubsection{Spring Linkage}

The spring linkage has a dual function. First, it holds the drive units against the pipe walls with enough force that the wheels do not slip. Second, it allows the half tractor to adapt to different size pipes and surface irregularities in the pipe walls without removal from the pipe or reconfiguration of the tractor. As can be seen in Figure 3 the spring linkage looks roughly like a parallel linkage mechanism. It does function like a parallel linkage when the tractor is in straight pipe. The links, however, are jointed and sprung at each joint so that when removed from the pipe they tend to curl up. The links bend in one direction only. Each of the smaller link segments is short enough to fit through a 1 inch elbow or tee. This flexibility allows the link to traverse corners which it could not fit through if it were rigid. The entire parallelogram that forms the spring linkage is hinged at the corners so that the drive units may pivot with respect to it. Figure 4 shows how a half tractor would drive through an elbow. First the base drive unit pivots through the elbow. Next, the linkage passes through the elbow segment by segment. The linkage then pivots through the elbow. Then, the top drive unit pivots through the elbow. 
Figure 3. Base Drive Unit

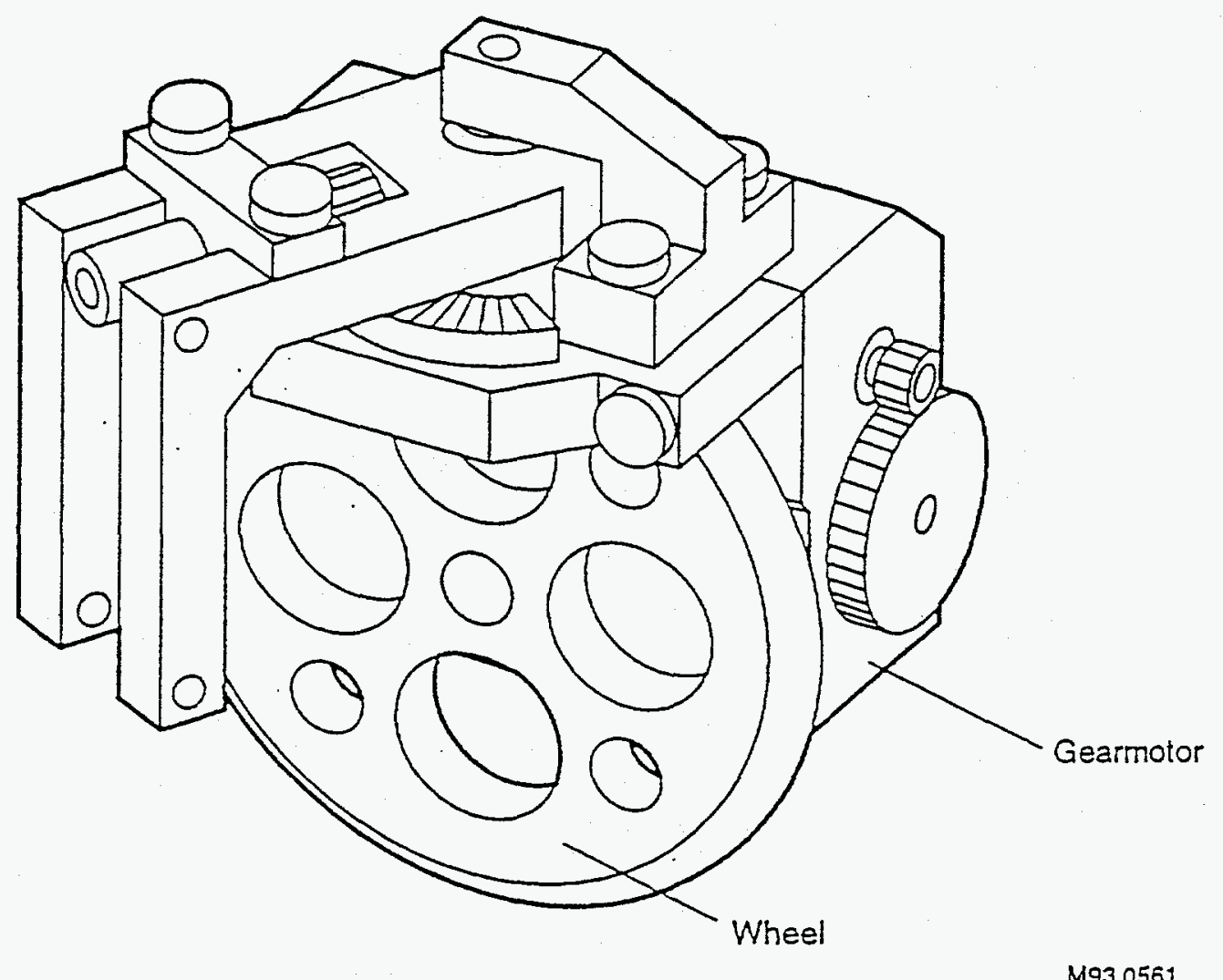


Figure 4. Half Tractor Traversing an Elbow

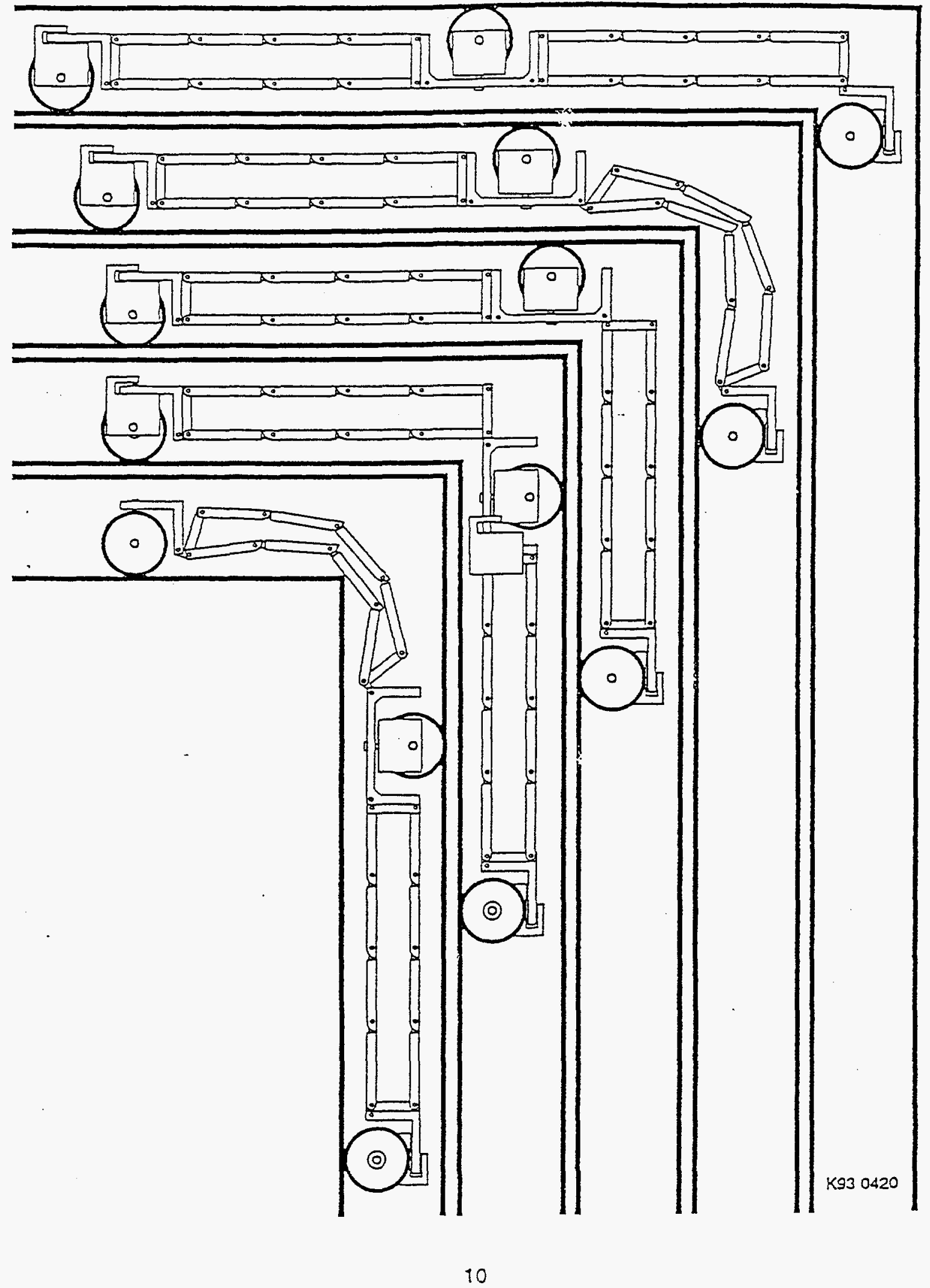




\subsubsection{Steering}

The steering mechanism allows the half tractor to be oriented with respect to the pipe elbow or tee. Because the half tractor bends within one plane only, that plane must be aligned with the elbow or tee. If the robot approaches a turn incorrectly aligned, the user stops it, rotates all three drive wheels 90 degrees, and spins within the pipe until the robot is aligned correctly with the elbow or tee. Then the drive wheels are straightened and the crawler passes through the turn. Using this method, the robot can select which branch of a tee or cross to enter. It may also orient itself so it passes straight through the tee or cross.

Because the wheels steer at the same time, they may be mechanically coupled and driven by a single actuator. That actuator is the second gearmotor located on the top drive unit. The top drive unit is coupled to each base drive unit with a series of flexible couplings. These couplings flex around the pipe elbow in a similar manner to the spring linkage. Figure 5 shows conceptually how the steering motion may be transmitted. Note that it is only necessary to steer the drive wheels in one direction 90 degrees. Once the drive wheels are fully turned, spinning within the pipe in either direction can be accomplished by driving the drive wheels at identical speeds in the proper direction.

\subsubsection{Payload Pods}

All electronics that must be located on the robot will either be located in payload pods or, if space allows, integrated into the half tractor hardware. Each pod must be small enough to fit through elbows in 1 inch piping. The number of payload pods is undetermined at this time and will be determined by the volume of onboard payload componentry. The pods will be connected with flexible joints so they will pass around corners independently. The pods will incorporate provisions to minimize their drag against the pipe walls. This will either be done with miniature coaster wheels or by coating the pod exterior surfaces with a low friction substance such as teflon. 
Figure 5. Motion Transmission in Steering System

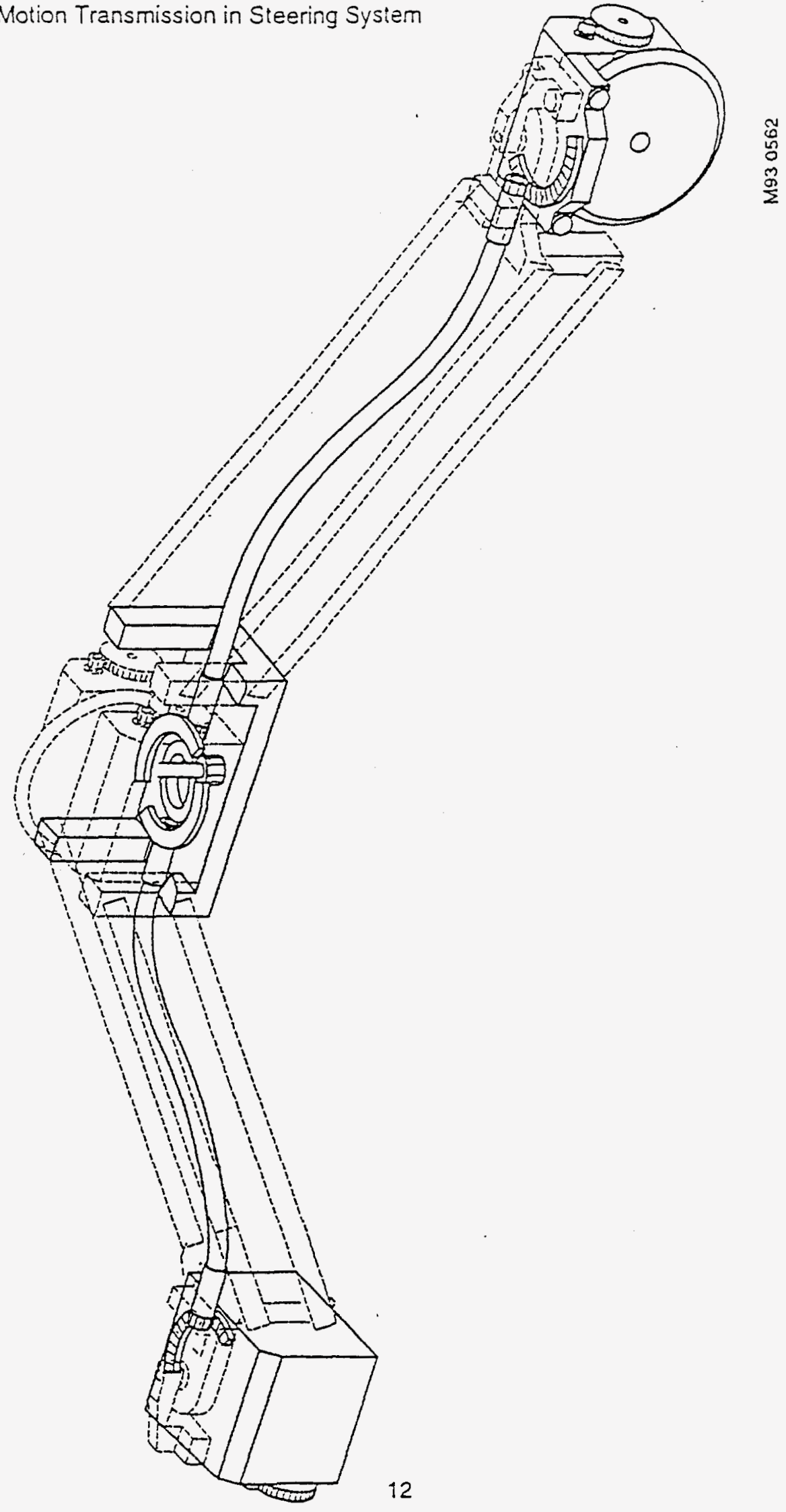




\subsubsection{Camera and Lights}

The onboard camera consists of a CCD video sensor chip and a lens which easily fits through a 1 inch elbow. There will be at least one camera at the front of the vehicle and possibly another at the rear. The camera will be pushed before the lead base drive unit and will use a simple spring linkage to guide it through the elbow. The light needed for the camera will be supplied by miniature incandescent lamps. If space permits, they will be located in a ring about the camera lens. If not, a larger more efficient light source will be located in a payload pod with the light transmitted to the front of the vehicle through a bundle of optic fibers.

\subsubsection{Tether Management System}

An optic fiber tether will be used for bidirectional data transmission. The tether will be carried on board and payed out as the robot traverses the pipe. This method was chosen because in systems where the tether is pulled behind the vehicle, the range of the vehicle for a given amount of pulling force will eventually be limited by the distance traveled or the number of bends encountered. The vehicle will loose traction with the walls of the pipe, or the load limits of the drive actuators will be met, or the tether breaking strength will be exceeded. By paying out the tether from the vehicle, the robot's range is limited only by the length of tether that can be carried onboard, or by signal degradation within the tether. Using optical fiber as a tether minimizes both of these limitations.

Methods for managing the tether range from (simple implementation) minimal tether protection to (complex implementation) maximum tether protection. The determining factor in deciding which method to use will be the durability of the fiber optic tether, which will be found through experience. The actual method will be selected by progressing through three alternatives described below.

\subsubsection{Totally Passive Method}

The first and most simple tether management system would trail the fiber passively both on the way out and on the return trip to the insertion point. This makes it necessary to carry twice as much tether as the crawler's range. The advantages to this system are mechanical simplicity and reliability. The disadvantages are the necessity to carry twice as much tether as needed and also the risk that the robot may damage the tether during the return trip. This risk is an unknown factor, so this will be the first system tried. 


\subsubsection{Passive / Active Method}

This tether management system would pay out tether passively on the trip away from the insertion point. When the robot begins to return, a powered reel would begin to pull the tether out of the pipe at the same rate that the robot travels. In this way, the robot would not have a chance to damage the tether by running over it. The disadvantage is that putting tension on an optic fiber that passes around bends may damage the fiber.

\subsubsection{Totally Active Method}

The totally active tether management system would use a powered tether reel onboard the robot to lay down and pick up the tether as the robot travels. This method provides maximum protection to the tether, but it also is the most complex to implement. It is hoped that the characteristics of the fiber will allow one of the more passive systems to be used. This choice will be determined through experience with the fiber itself.

\subsubsection{Emergency Retrieval}

Provisions for Emergency Retrieval of the robot from the pipe will be incorporated. The force necessary to pull the vehicle from the pipe will be determined both through calculation and through testing. As the robot moves through the pipe, it will passively trail a thin, strong line. This line will be of sufficient strength that the robot may be pulled from the pipe if necessary. The line may be of monofilament or another material as determined through experience with emergency retrieval methods.

\subsection{Electrical}

The electronics for the SPCS are split into two parts, the control station and the pipe crawler. These two parts are connected with a fiber optic tether for data communications. Figure 6 depicts a functional block diagram of the electrical system. The control station is a portable ac-powered unit that contains video monitors, a control computer, and video recording equipment. The pipe crawler carries onboard battery power that runs all onboard systems. It carries a number of microcontrollers that run low-level system functions such as sensors and motor drivers. The robot is controlled and sends out data through the optic fiber tether. 
Figure 6. Electrical System Block Diagram

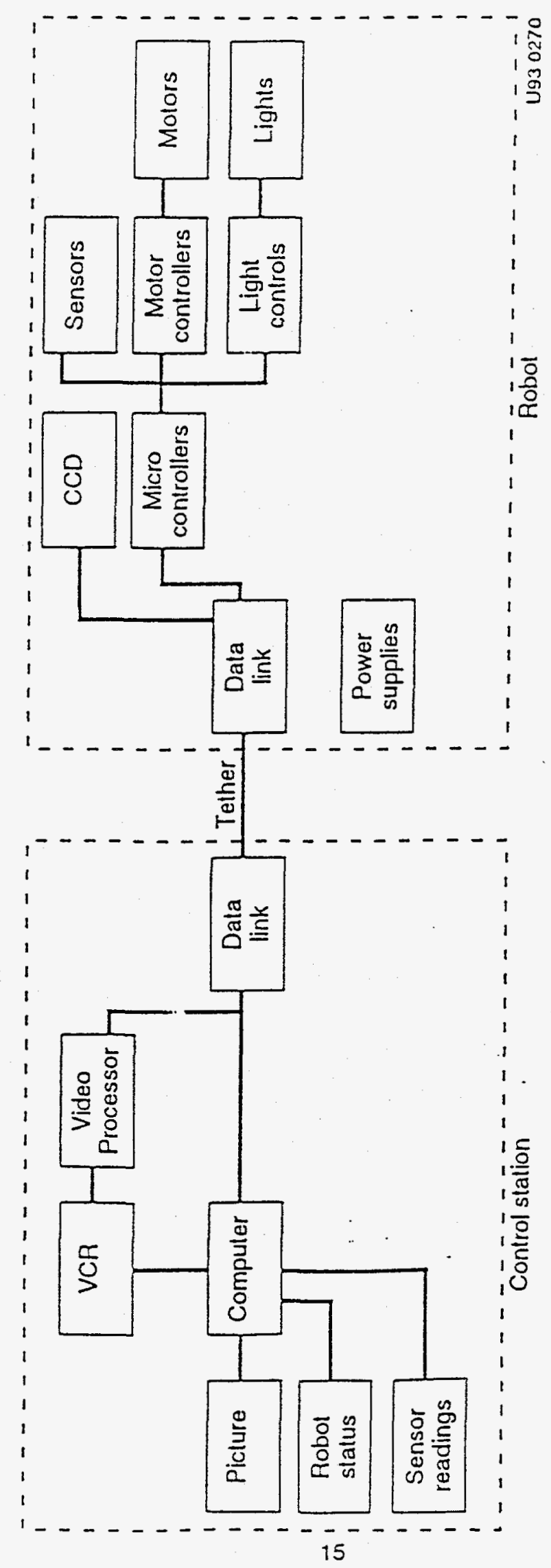




\subsubsection{Motor Control}

The dc motors will be powered by onboard batteries. Pulse width modulation (PWM) will be used to control the speed of the motors. Using PWM reduces noise levels in the system and is more efficient than using an amplifier to vary a linear voltage level across a dc motor. PWM uses a very fast pulse train of varying duty cycle to vary the average voltage across the dc motor. This method is shown in figure 7 .

An onboard microcontroller receives commands from the control computer via the optic data link. The microcontroller handles the low-level control functions such as driving the PWM chips and receiving encoder feedback. The microcontroller may report status information back to the control computer, such as steer motor limits reached, distance traveled, etc.

Figure 8 illustrates the block diagram of the closed loop motor control system. Closed loop control is accomplished by feeding back signals from special optical encoders to the microcontrollers. Utilizing feedback control will allow the vehicle to hold its position in a vertical pipe for characterization and inspection purposes. Some radiation sensors have a maximum speed at which they may pass over the surface they are scanning. In long stretches of pipe, open loop control would mean that the operator would have to attempt to hold a certain speed for relatively long periods of time. closed loop speed control lets the operator set a desired speed and the robot will hold to that speed. This should greatly enhance usability of the system.

\subsubsection{Video System}

The video system consists of a remote head camera containing a single CCD video sensor chip and an image processor. Several analog signals are passed between the processor and the CCD chip to produce the video signal at the processor. These signals are digitized and sent through the fiber optic data link. On the other end of the link, $D / A$ converters convert the digital signals back to analog. Figure 9 shows this process.

This method allows the multiconductor cable that normally links the CCD head with the video processor to be replaced with a high speed bidirectional fiber optic digital data link. The processor is located at the control station, and the $\mathrm{CCD}$ head is located on the robot. It may also be possible to use the same circuitry for multiple CCD chips, selecting which CCD operates at any given time. If two cameras are used, only one will be powered at any time. Thus, only one video power supply is required and the amount of video data transmitted is minimized. 
Figure 7. Pulse with Modulation

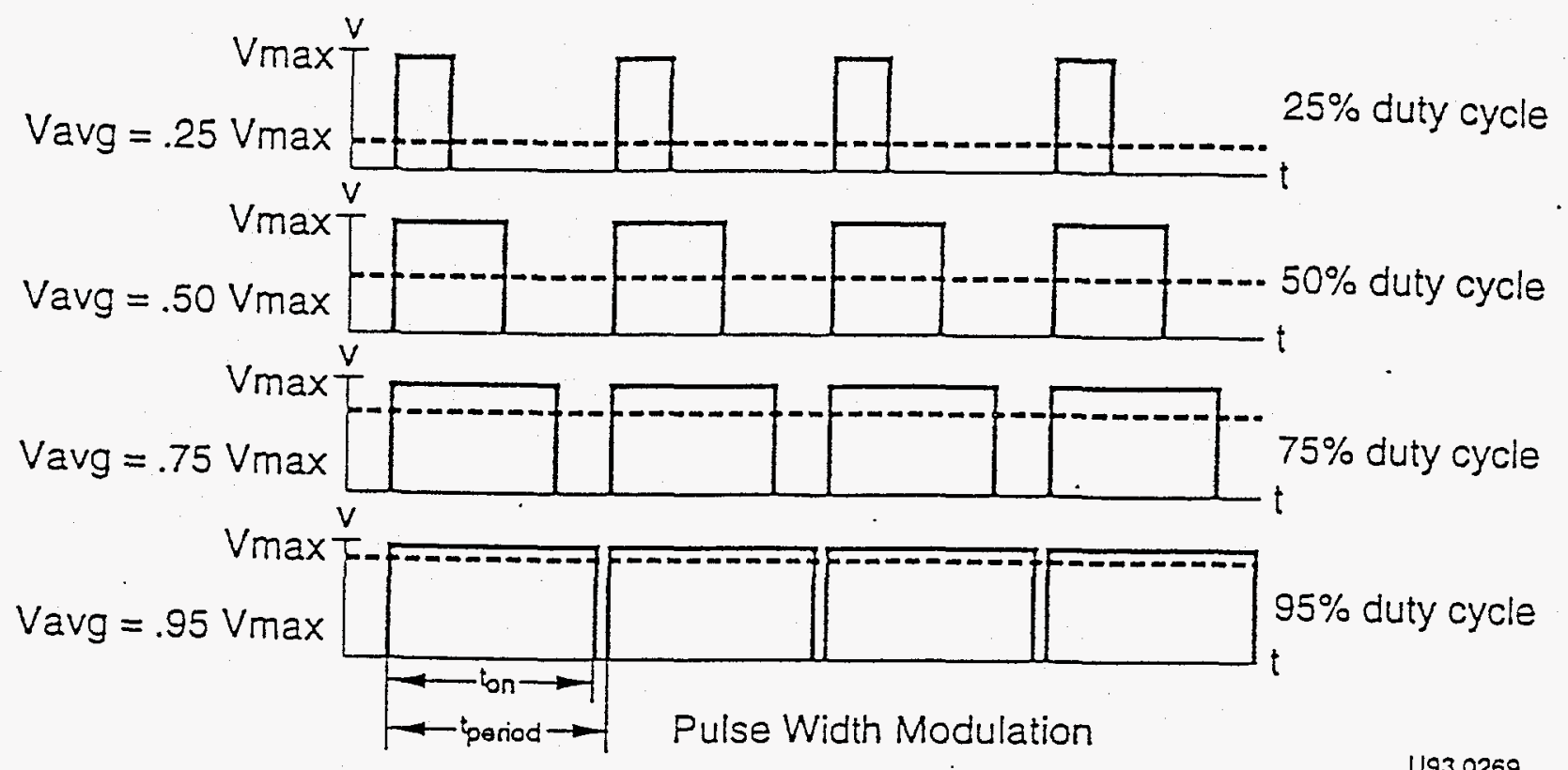


Figure 8. Pipe Maze

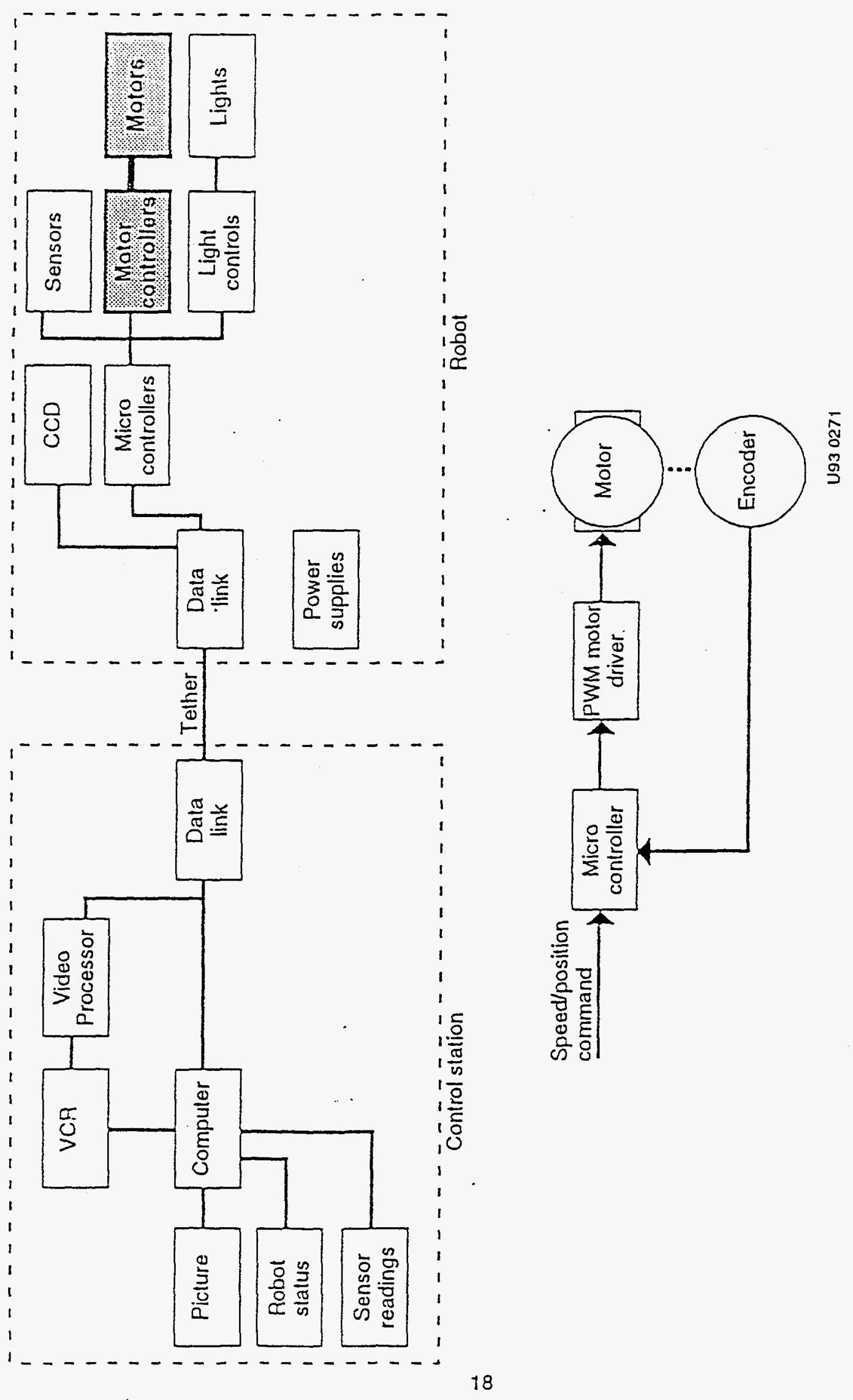


Figure 9. Video System Biock Diagram

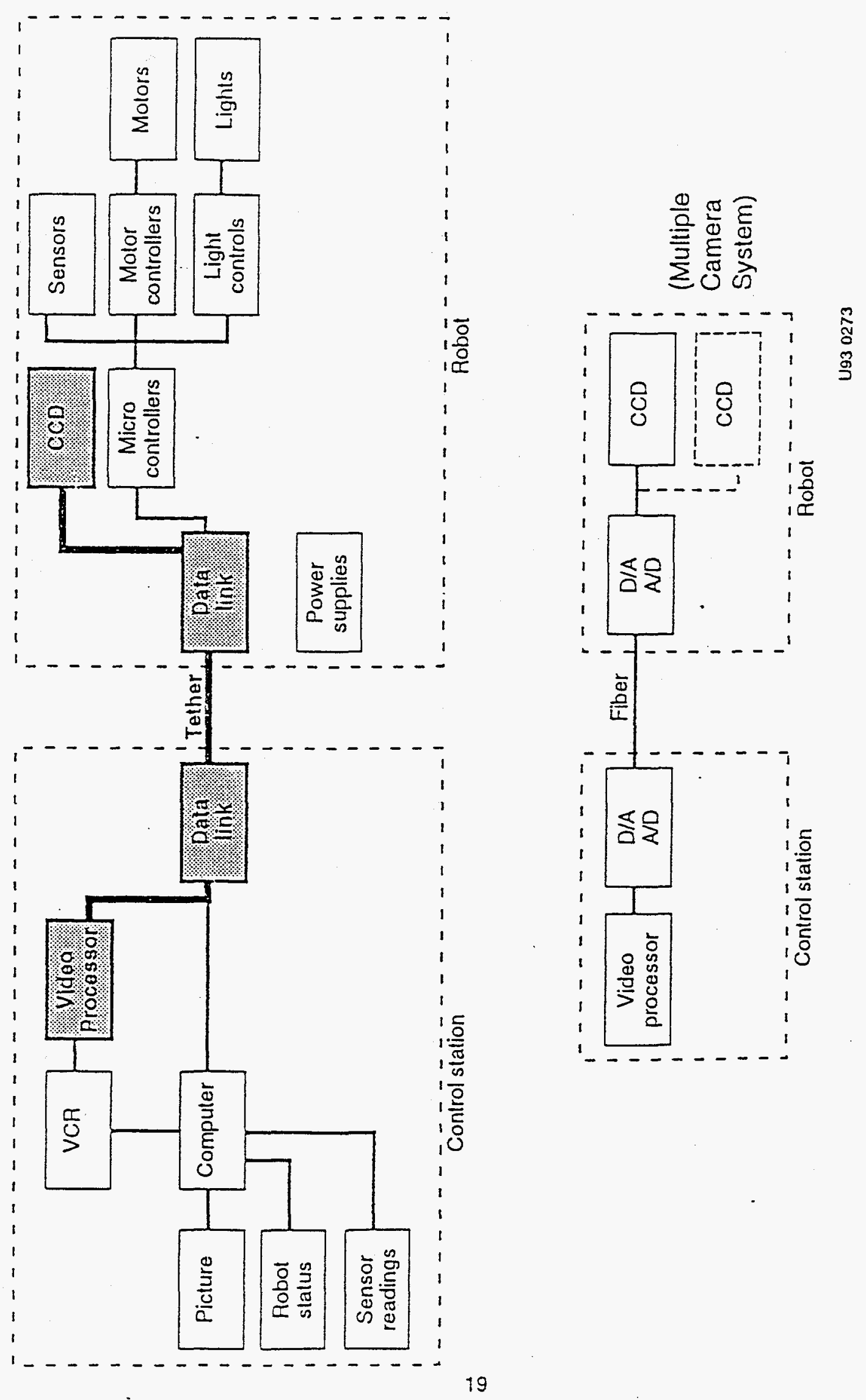




\subsubsection{Power System}

The power for the robot is supplied by onboard batteries. Depending on the voltage levels and current requirements needed, multiple power supplies will be constructed. This allows optimization of battery volume and mass. For example, the dc drive motors are a low voltage, high current load. A single battery that is relatively large (giving high current capacity) might be used for each motor. On the other hand, most of the digital circuitry is higher voltage, but with very low current draw. A series of very small batteries (giving the required voltage level) would be used.

In a 1 inch pipe crawler, the primary concern is that weight and size must be minimized. This is the driving factor in the selection of the battery's chemistry and power capacity. Initial power calculations indicate that onboard power can be achieved using available battery technologies such as lithium.

\subsubsection{Sensor Interface}

To allow for different sensors to be used, a microcontroller passes sensor data back to the control station. This allows the sensor circuitry to use a standard data interface. Future sensors will also be designed to use this interface, thus providing quick changeouts of sensors.

The control computer records sensor data and presents it to the operator. This eliminates manipulation and storage of the sensor data onboard the robot and allows for minimized control electronics at the vehicle.

\subsubsection{Data Communications}

Data that must be transferred between the control computer and the robot is transmitted over a high speed bidirectional fiber optic digital data link. This consists of a single optic fiber with a digital transceiver at each end. Figure 10 is a block diagram of the digital data link. The transceivers are matched so that data transmission in one direction utilizes $1300 \mathrm{~nm}$ wavelength light and in the other direction utilizes $850 \mathrm{~nm}$ wavelength light. This allows the bidirectional data transfer over the single fiber.

The types of data transferred are $C C D$ chip data, commands from the control computer, sensor data, and status information from the robot. All this data must be multiplexed onto the very high speed single fiber data link. The CCD chip data will be continuously bidirectional, with timing signals from the video processor triggering CCD output signals. The control computer instructions 
Figure 10. Data Communications Block Diagram

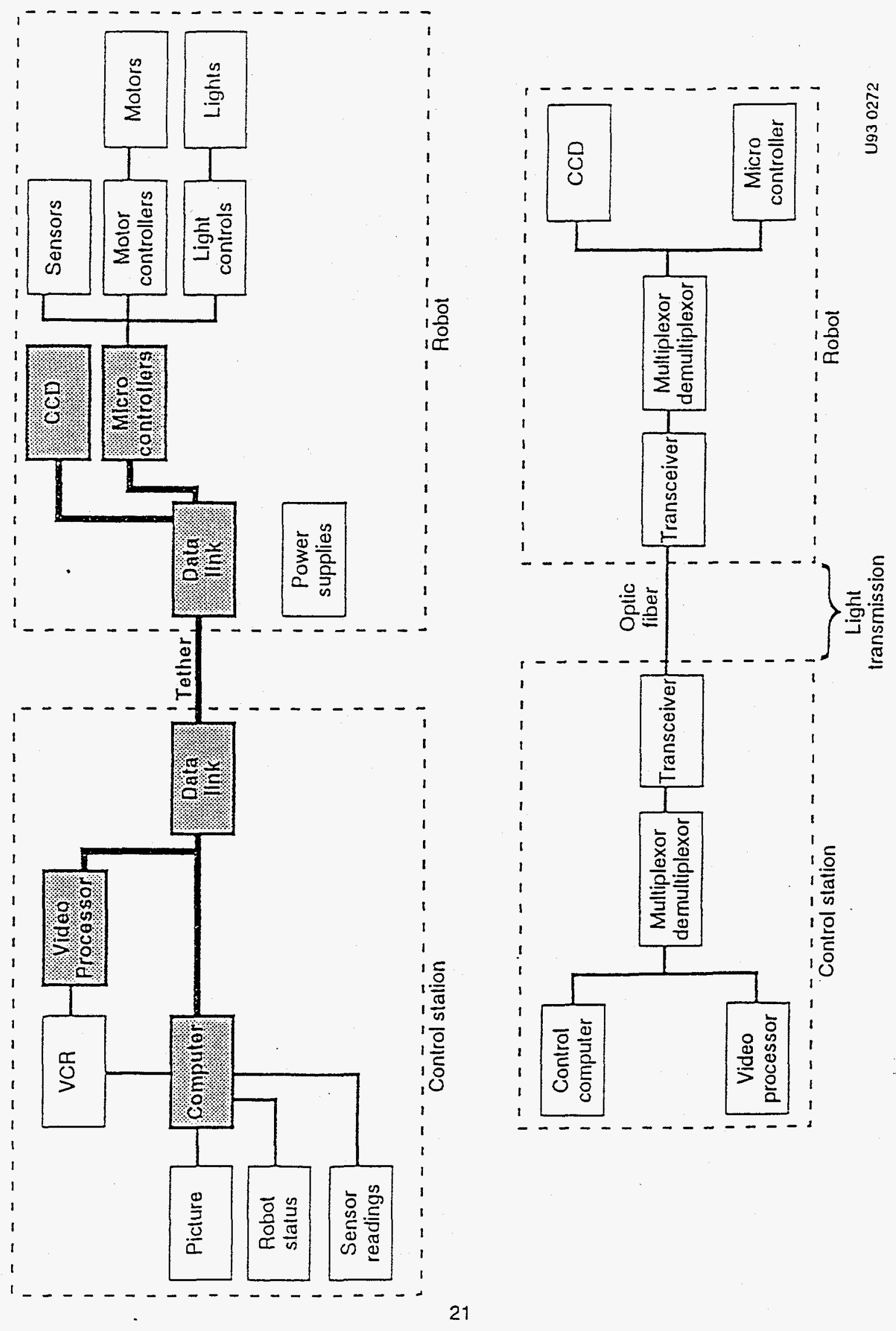


consist of robot commands and information requests. Robot commands direct the pipe crawler's actions and are unidirectional. Information requests query for sensor data and robot status information and are bidirectional.

\title{
4.2.6 Control station
}

The control station lets the operator direct the actions of the robot, observe live video images, and record video and sensor data. The user will be able to control speed and orientation of the robot and operation of the sensors. There will be a display showing the robot camera video images, one showing sensor readings, and one showing robot status information. This information may be presented in either textual or graphical forms.

\section{Program Goals}

The development of the SPCS is broken into two stages. FY 94 will produce a usable inspection system on the upper range of pipe. This is planned to be from approximately 2 to 3 inches in diameter. FY 95 will produce a usable inspection system for the full range of piping from 1 to 3 inches internal diameter. FY 96 will consist of technology transfer activities.

\subsection{FY 94}

This system will have drive units that will fit in 2 inch piping. The tractor will change from 2 inch to 3 inch piping "on the fly." The motor control will be open loop. The optical encoders will be mechanically incorporated into the tractor, but may not be incorporated electrically. The robot will pull an electric cable tether. This tether will consist of a camera cable, a serial bidirectional data link, and power lines. There will be only limited onboard power supplies; the rest of the power will come through the tether.

\author{
5.1.1 Technologies To Be Developed. \\ - gearmotors \\ - drive units \\ - tractors \\ - camera mount \\ - payload pods \\ - wire tether management system \\ - de motor drive circuitry \\ - radiation sensor (beta and gamma) \\ - fiber optic encoder mechanical integration \\ - serial data link \\ - data communications protocols \\ - robot low level controls \\ - robot high level controls \\ - control station/user interface
}




\subsubsection{Deliverable performance}

- traverse pipe maze (Figure 11) on upper range of pipe

- locate a beta source (e.g., lantern mantle) in the maze

\subsection{FY 95}

This system will have drive units that will fit in 1 inch piping. The tractor will change from 1 inch to 3 inch piping. The motor control will be closed loop using fiber optic encoders for position feedback. The robot will use an onboard optic fiber tether for communications. Power supplies will also be located onboard the crawler.

\subsubsection{Technologies To Be Developed}

- miniaturize all existing 2 inch systems previously developed

- replace serial link cable with minimal optic fibers

- fiber tether management system

- onboard power supplies

- optical encoder electrical integration

- closed loop position and speed controls

- electronics for operating CCD chip over optic fiber

- sensor interface for multiple sensors

\subsubsection{Deliverable Performance}

- traverse pipe maze for 1 inch to 3 inch piping

- locate a beta source (e.g., lantern mantle) in the maze

\subsection{FY 96}

The focus of FY 96 will be technology transfer activities. It is probable that CRADAs will have been established along the way to help develop component technologies. The complete integrated system should be licensed as well. 
Figure 11. Pipe Maze
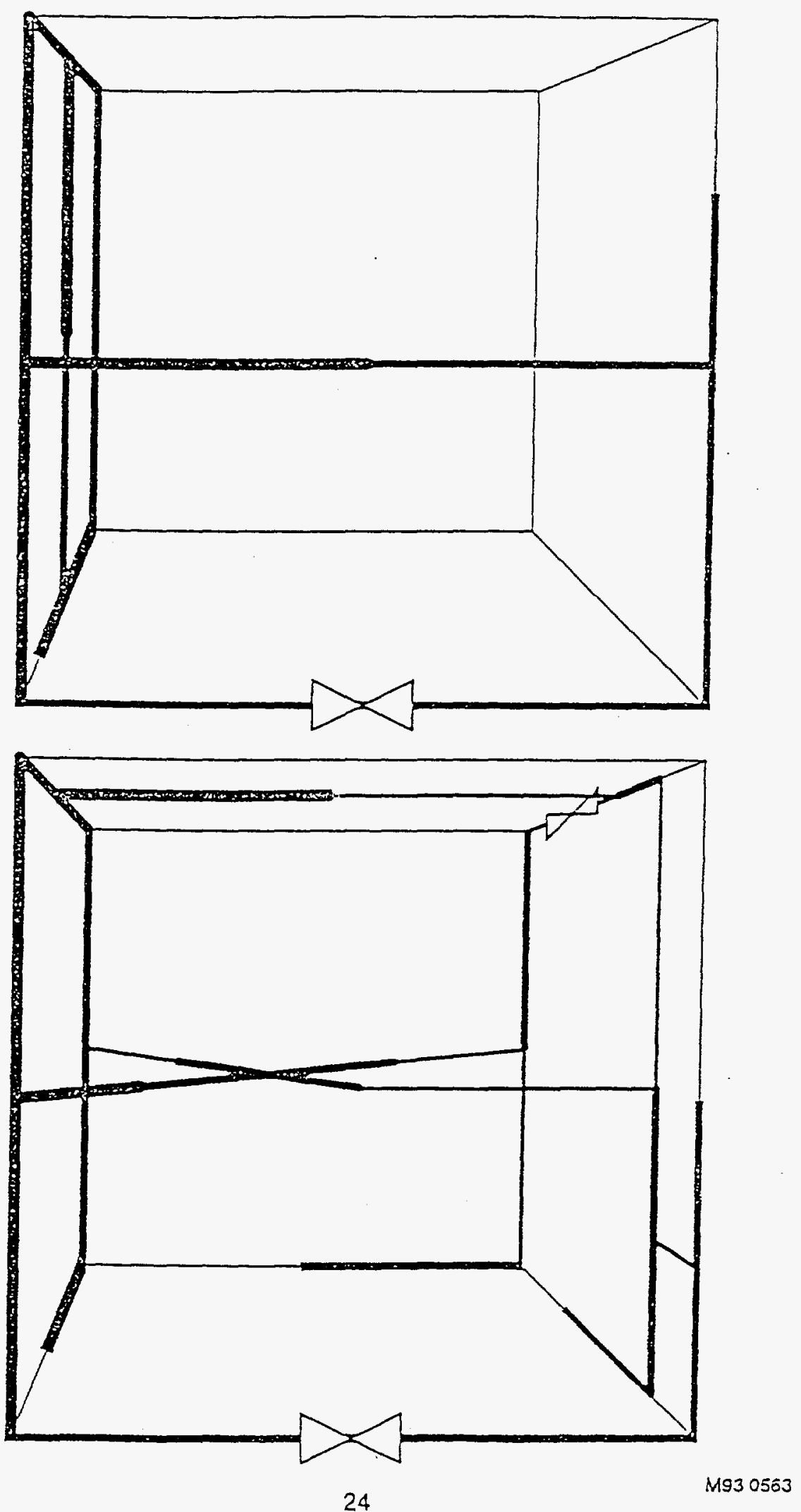